\title{
Boundaries and Boundary Marks Substantive Cultural Heritage of Extensive Importance
}

\author{
P. Waldhaeusl, H. Koenig, R. Mansberger \\ The Austrian Society for Surveying and Geoinformation \\ Working Group "World Heritage Title for "Boundaries and Boundary Marks" \\ pw@ipf.tuwien.ac.at
}

\section{KEY WORDS: Boundaries, Cadaster, Landmarks, Land Registry, State Borders, Tangible Cultural Heritage UNESCO, World Heritage,}

\begin{abstract}
:
The Austrian Society for surveying and Geoinformation (ASG) has proposed to submit "Boundaries and Boundary Marks" for the UNESCO World Heritage title. It was time that boundaries, borders and limits of all types as well as ownership rights would find the proper attention in the global public. Landmarks symbolize the real property and the associated rights and obligations, in a figurative sense, the property generally and all legal limits. A democratic state of law is impossible at today's population density without a functioning land administration system with surveying and jurisdiction. As monumental World Heritage representatives of the geodetic artwork "Boundaries and Boundary Marks" are specifically proposed: remaining monuments of the original cadastral geodetic network, the first pan-Austrian surveying headquarters in Vienna, and a specific selection of outstanding boundary monuments. Landmarks are monuments to the boundaries which separate rights and obligations, but also connect the neighbors peacefully after written agreement. "And cursed be he who does not respect the boundaries" you wrote already 3000 years ago. Boundaries and Boundary Marks are a real thing; they all belong to the tangible or material heritage of human history. In this context also the intangible heritage is discussed. This refers to oral tradition and expressions, performing arts; social practices, rituals and festive events; as well as to knowledge and practices handling nature and the universe. "Boundaries and Boundary Marks" do not belong to it, but clearly to the material cultural world heritage. "Boundary and Boundary Marks" is proposed to be listed according to the criteria (ii),(iv),(vi).
\end{abstract}

\section{FILLING THE GAPS}

Younger recommendations and decisions of ICOMOS, the International Council on Monuments and Sites, and UNESCO concern an extension of the "classical" term Cultural Heritage (Jokilehto, 2005). In addition to single architectural monuments, monument-groups, towns and the natural and mixed heritage, world heritage shall include now also monuments of industry and technology and "architecture" in a broader sense, as Hans Hollein ${ }^{1}$ included even industrial design, and further facilities for traffic and transportation, as roads and bridges, for water supply, sewage treatment and communications. Missing types of properties shall be added: Filling the gaps and diversification are required. Of course, UNESCO does expect very special examples, the typical, the unique, and the interesting, with cultural, historical, and aesthetic spirit, and in any case of outstanding universal value, integrity, and authenticity.

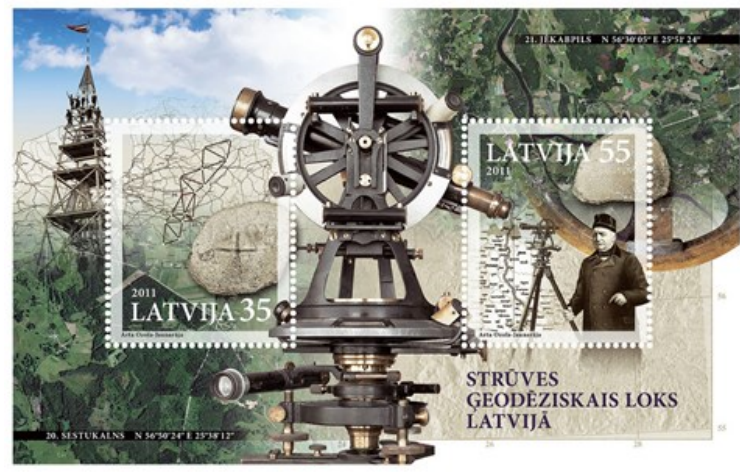

Figure 1. The Struve Geodetic Arc on stamps of Latvia. Winner of the Latvian stamp competition 2011. (Philately News, 7.3.2012)

\footnotetext{
${ }^{1}$ Hans Hollein (1934-2014) Austrian star-architect, designer, sculptor, object artist. "Everything is Architecture"
}

\section{THE STRUVE GEODETIC ARC}

The first World Heritage Property out of the technical area of geodesy and typical for Filling the Gaps (Jokilehto, 2005) was the "Struve Arc", which became UNESCO World Cultural Heritage Site in 2005, a meridian arc of $2820 \mathrm{~km}$ length measured by great pioneers of geodesy from 1816 until 1855 , by means of a triangulation chain reaching from the Norwegian North Cape to the Black Sea. That was a scientific project of natural sciences for the determination of the figure of the earth to be studied and computed in a vertical section of the globe. (UNESCO-WHC, 2005)

\section{BOUNDARIES AND BOUNDARY MARKS}

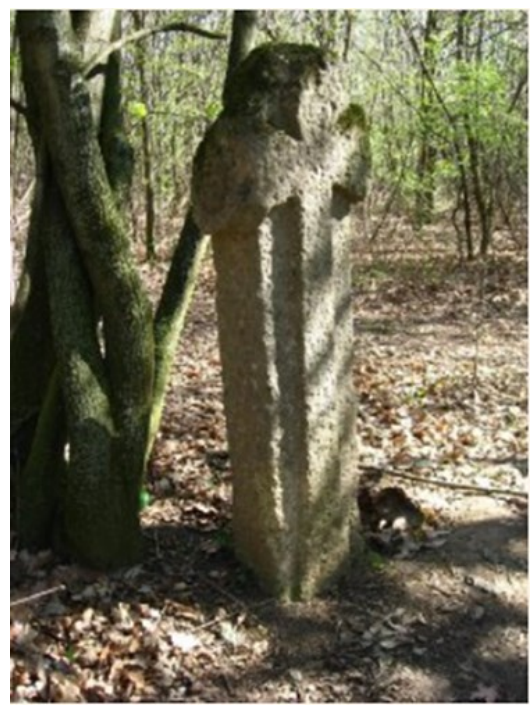

Figure 2. Boundary stone of the $15^{\text {th }}$ century in Lower Austria

"Oara"-stone, from Latin ora $=$ hem or border. (Paul 1988), (Copyright Harald Hartmann) 
The Austrian Society for Surveying and Geoinformation (ASG) has proposed to submit another geodetic property for the UNESCO World Heritage title: "Boundaries and Boundary Marks". It was time that boundaries, borders and limits of all types as well as ownership rights, would find the proper attention in the global public. It is a fine and giant precision meshwork all over the country respectively over countries and even continents. Another man-made world wonder. Landmarks are symbolizing the real property, the associated rights and obligations, and in a figurative sense they are symbolizing ownership in general, and all legal limits. A democratic state of law like Austria would be impossible without a functioning land administration system with surveying and jurisdiction.

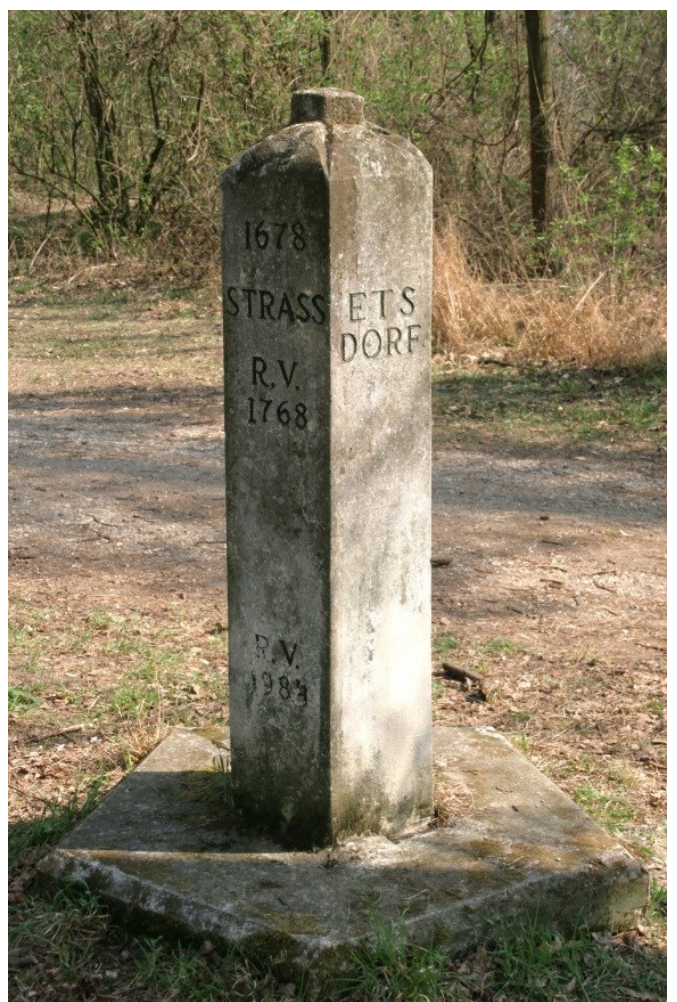

Figure 3. This pentagonal boundary stone from 1678 connects six parcels, five cadastral communities of four political communities in two different districts, a rare situation (Photo H.Koenig)

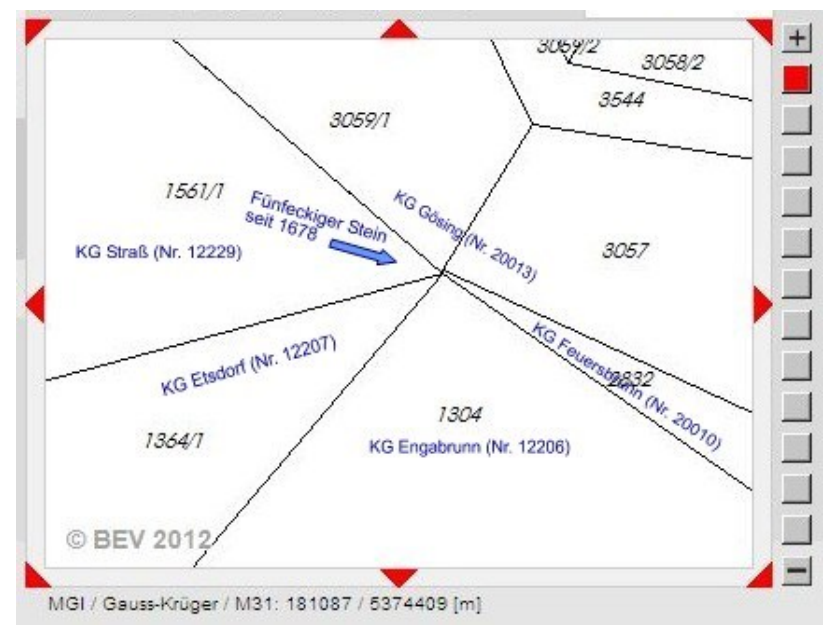

Figure 4. Extract from the cadastral map of today, showing the multi-crossing of the pentagonal boundary stone (Source BEV)
Geodesy means "dividing the earth", the country, the areal land. Geodesy fixes the division of landscapes as defined and agreed by the people e.g. in farmland, forests, roads and construction sites, in pieces of land according to the legally agreed rights and obligations. The results are visible in the nature as well as on the maps as boundaries between land properties and administrative units. Without its knowledge neither spatial planning is possible, nor land use, neither landscape design, nor the necessary land administration. The network of boundaries has great importance for a peaceful and well-functioning coexistence of people, of peoples, and of generations. Without it mankind had permanent chaos.

It was quite natural to define for Boundaries and Boundary Marks a new World Heritage project (Waldhäusl, 2014). It is exactly matching the modern objectives of UNESCO. In contrast to the definitely finished mere scientific project of the Struve Arc it is per definition a permanent task concerning legal, fiscal, social, economic and ecologic problems of mankind. Boundaries are horizontally defined; they are something touchable, static and real, and also something special:

$\circ$ Because they were defined by the neighbors together and agreed as limits of their real property in the nature.

- Because they have been measured and geocoded by an authorized and independent Chartered Surveyor and documented in a public Cadaster and a public Land Register.

- Because any Chartered Surveyor can reconstruct the boundaries again on basis of the cadastral data.

- Because this way they and the areas they enclose have gained legal certainty.

It is necessary to recognize the limits in the nature, because that is where the land rights are changing, and to observe them, so when crossing or driving, in agriculture, in the construction of buildings, in inheritance or sale. For easy recognition of the limits are boundary markers of various kinds: metal marks, crosses in the rock, oak pegs, boundary stones, etc. Especially the older boundary stones are often unique and artistically sophisticated designed; they deserve special protection for that reason alone. Today the boundary marks are endangered, mainly through agricultural machines and vehicles, but also due to theft, although they are protected by specific legal provisions.

In Austria Geodesy has assembled artfully all parcels of land by a network of boundaries, which is expanded over an entire country and is associated with just such networks in neighboring countries. A network of millions ${ }^{2}$ of precisely measured and documented boundary meshes, which prevent landowners from unnecessary border disputes. This ensures real estate property and protects legally country and society. This is all the more significant, the more people demand for food, the more valuable the land and its yield will be. Mankind is multiplying; land cannot be multiplied.

For this world heritage project specific objects are proposed as material representatives of the real network of boundaries, namely

- A few landmarks especially prominent due to its location or history, its special shape or art. They will be selected from different parts of Austria.

${ }^{2}$ Austria of today has $80.000 \mathrm{~km}^{2}$ with more than 35 million of boundary points. The former Austrian-Hungarian Monarchy had $677.000 \mathrm{~km}^{2}$ and more than approximately 300 million of boundary points, which have been measured within 50 years.(1817-65) 
$0 \quad$ Some special monuments of the cadastral triangulation, that was the initial geodetic precision framework for the surveying of boundaries and boundary marks so that the sum of them could become a whole. This includes some major monuments such as endpoints of the baselines, necessary for scaling of the network (e.g. that in Wiener Neustadt), zero-points of the cadastral co-ordinate systems (e.g. the tower of St. Stephen in Vienna), and very old stone-marks of the cadastral triangulation.

- The most important office buildings of the institutions responsible for cadastral surveying and land registry, such as the first total-Austrian Military Geographic Institute (MGI) behind the Vienna City Hall and possibly also an important court with early cadastral archives.

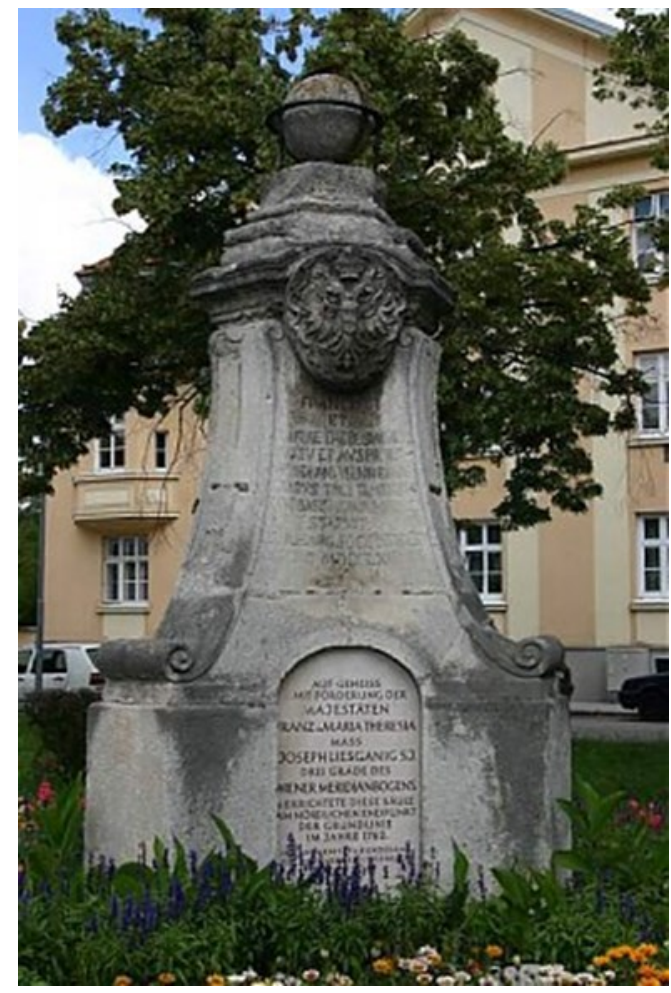

Figure 5. The Liesganig Monument in Wiener Neustadt, erected 1762 , reminds on the earliest framework triangulation for topographic and cadastral mapping of the Austrian-Hungarian Monarchy. (Source: Monument Protection Association Wiener Neustadt, http://www.denkmalschutz-wn.at)

Today, the network of boundaries with its boundary marks, which contains all parcel-boundaries and the administrative limits of the communities and districts, is kept up to date by some hundred certified surveyors, and is centrally managed by the Federal Office of Standards and Surveying (BEV) together with the Courts for Land Registry, everything public and transparent for all citizens. The BEV is also responsible for the national borders. This Land Administration System (LAS) has been developed during centuries by the best experts in technology, management and law. Initially it has served for fair taxation of agricultural production areas, only, but over time it was extended to all land and developed into an important tool for regional planning, for best possible management of land and soil as well as for secure proof of ownership. It now forms a very important basis for democratic administration and economy.
The whole opus "network of all boundaries" is an enormous technical, legal and organizational performance by great people of a wide variety of disciplines. It has been further developed from epoch to epoch by and for generations in order to secure technically and legally land ownership and fair burden-sharing. This opus is a large entity like an old city, built up by various generations in different eras, however, in its early days it became its special character.

In the case of Austria's network of boundaries the most impressing act was the foundation of the outstanding Franciscan Cadaster 23 Dec. 1817. It was the first uniform system of a big empire in the world managing all its parcels of land with boundaries, recognized by both sides under oath and well surveyed by (today) Chartered Surveyors and documented in technical cadastral and legal land registry offices. All the documents are publicly available. The boundaries are restorable at any time on basis of these documents. Correctly broad scope will be given to the Franciscan Cadaster in the Austrian request for World Heritage. By the Treaty of St.Germain-en-Laye, Sept. 10, 1919, this historic achievement of the Austrian administration of the 19th and 20th century has been partitioned and distributed among the successor states of the Habsburg Empire. Most of these successor states have used the old-Austrian cadaster and land registry as basis information, but created their own LAS. Only Austria has maintained and further developed its own system continuously, which serves today many countries of the world as a model.

In the nomination file for the title of World Heritage the original meaning, the historical idea of "limit, boundary, border and frontier" and the change in their historical significance will be described in detail in parallel to the technical and legal aspects. This is particularly important for the understanding of the idea of this UNESCO project and could lead to the proclamation of a „Year of pacified borders".

The application for the "World Heritage title for the network of Boundaries and Boundary Marks" will be drafted so that also other states, especially the neighboring states, can easily join it later with their respective Land Administration System and its associated monuments. Of course they need to describe their LAS from their own perspective themselves, its historical development, practical use and importance. But the material core applies to all: Highly qualified "agreed" Boundaries and Boundary Marks in a constitutionally and legally protected, public, neutral and functioning Land Administration System.

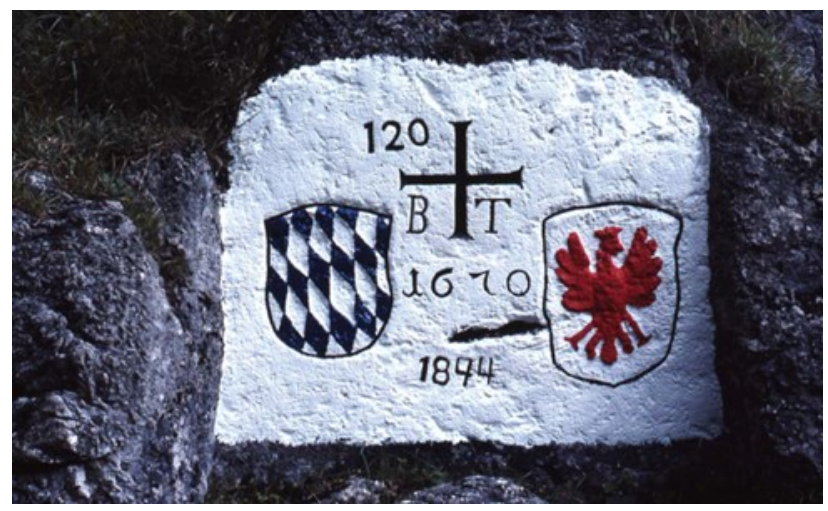

Figure 6. State border mark between Tyrol (Austria) and Bavaria (Germany) from 1670. (Photo H. Koenig) 


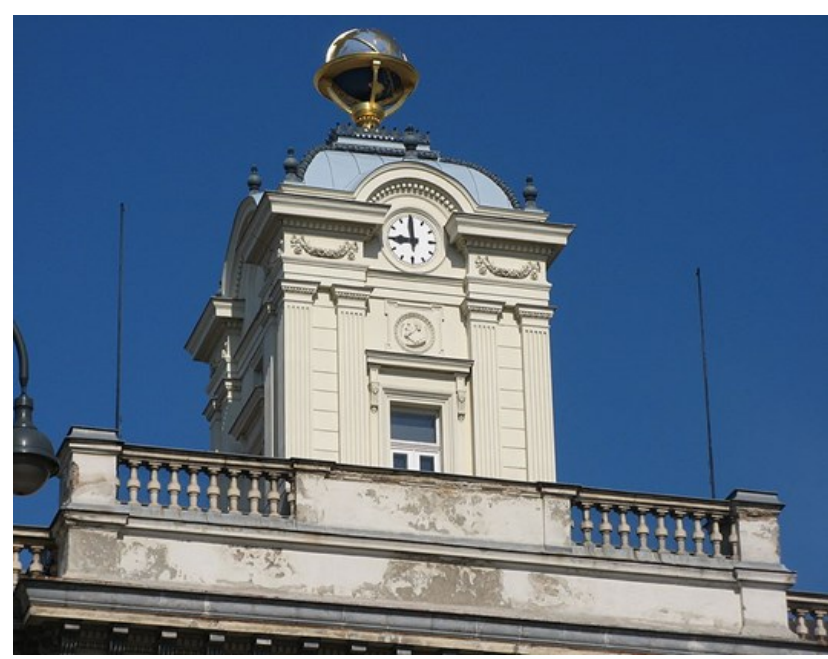

Figure 7. The tower-pavilion of the first Pan-Austrian Military Geographical Institute in Vienna (1842). A round relief portrait below of the clock reminds on Johannes Kepler (1571-1630), the elected patron of the building (Source: BEV)

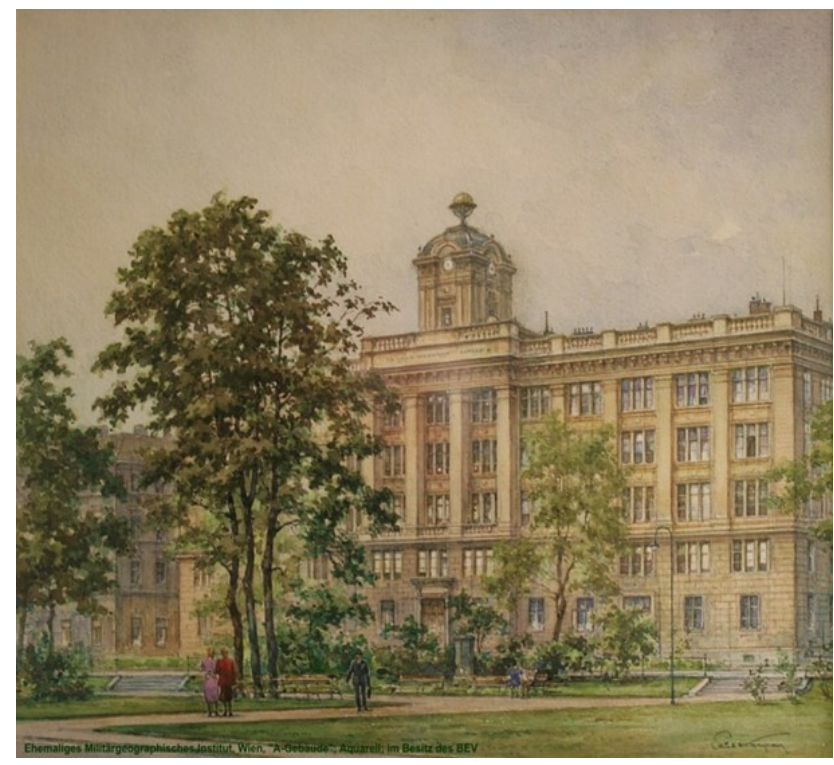

Figure 8. The Military Geographical Institute served as central office for the cadastral survey from 1843 until 1983, when the Federal Office (since 1921) moved to a bigger building. The cubic structure consists of a two-storey base zone, similar to the three upper floors, which are divided by giant Doric pilasters. In the centerline a tower-like pavilion was set up, which served as an observatory until 1927. (Painting after 1871, Source BEV)

\section{THE OUTSTANDING UNIVERSAL VALUE}

In the focus of the submitted application is what a Land Administration System is documenting: Boundaries and Boundary Marks. You can also say with a clear conscience, that the technical cadaster and the legal land registry are - in the sense of the operational guidelines for UNESCO World Heritage sites (UNESCO-WHC, 2013) - the perpetual management system guaranteeing authenticity, integrity, and the special outstanding universal value of Boundaries and Boundary Marks in the long term. Cadaster and Land Registry are a known good and legally, even constitutionally secured system for the management of all borders - and in a broader sense - of property and peace.

The publicly accessible, legal and technical documents on the land property in the legal land registry and the geodetic cadaster secure the necessary knowledge about all lot-referenced legal and geometric limits and thus the continual existence of these borders and - as a consequence - the practical use of land. Landmarks should be seen as petrified parts of the boundary treaties concluded between neighbors, as reminding memorials, which let us remember the history of the relevant treaties and contracts, but also other limits. They are also warning monuments for mankind, like cathedrals, castles and frontier walls with their specific meaning. Boundaries and Boundary Marks are recalling the historical development of civilization, of the put down roots of mankind and the genesis of ownership. Boundaries and Boundary Marks are also a material basis for cultural landscaping, for social peace, democracy and economic development. The great importance of universally recognized international borders for peace and cooperation need not be highlighted separately. Mankind's longing for order and peace is the reason for the outstanding universal value of Boundaries and Boundary Marks. No society is interested in chaotic neighborhood.

The practical advantage of such a Land Administration System of publicly and legally protected boundaries is immense. That is important to be demonstrated in the application significantly. The society is not enough aware of the many important applications of a safe and public Land Administration System, of the many advantages and consequences, which are e.g.:

- Avoiding and settlement of land disputes;

- Promotion of the credit system and thus of the entire economy;

- Back up of the regulated land trade;

$\circ \quad$ Fixing of the superimposed boundaries of municipalities, cities, provinces, countries and states;

- Basis for local, regional and inter-regional planning;

- Planning, construction and management of supply and waste;

- Realization of traffic connections, for transport and supply;

- Management of Civil protection;

- Planning, administration and protection of natural and cultural landscapes;

- Planning and acting for environmental protection in the country;

- Demarcation of regional rights, such as for hunting, fishing, mining, water;

And so on and so forth.

It is also worth noting that Austrian experts have been and are used as consultants by and for many countries and that the Austrian LAS is used by many countries as a model for the reorganization of their Land Administration Systems. The theme Boundaries and Boundary Marks will encourage further fundamental research of resp. together with Austrian cadaster Experts (Krinzinger, 2013)

\section{TANGIBLE CULTURAL HERITAGE}

Although linked with many legal and organizational aspects, which are immaterial, Boundaries and Boundary Marks are something completely material, as well as the monuments of the initial triangulation and the historical buildings of personnel and archives for the initial production of the Land Administration 
System. Real and touchable heritage is part of the tangible, not of the intangible heritage. In discussions on the subject was proposed sometimes to associate Boundaries and Boundary Marks with the intangible heritage world because of the many important written documents and the many applications. It was clarified quite soon that Boundaries and Boundary Marks are essentially material and do not belong to such World Heritage the UNESCO would assign to the intangible. What UNESCO and ICOMOS mean by Intangible Heritage is described exactly in the UNESCO Convention on Intangible Cultural Heritage (UNESCO, 2003)

This Convention was preceded by long discussions in ICOMOS inspired particularly by Africa (Tomaszewski, 2003; Munjeri, 2003) which led finally in 2003 to unanimous decisions of the General Assemblies of ICOMOS in Victoria Falls, Zimbabwe, and UNESCO in Paris. It was high time, understandable and correct, to find a World Heritage solution for customs, beliefs, traditions, e.g. for the belief in Mazu (the goddess of sea, Chao Chin-Fang, 2004), for smoking the peace pipe, for the dressage of Lipizzaner horses, for distillation of gentian schnapps, for the yodeling as well as for the Vienna coffee house traditions, so that the special, traditional, typical, the distinguishing of all of us does not disappear in a global unit-culture. The UNESCO Convention lists for the intangible cultural heritage the following domains:

a. Oral traditions and expressions, including language as a vehicle of the intangible cultural heritage,

b. Performing Arts,

c. Social practices, rituals and festive events,

d. Knowledge \& practices concerning the nature and the universe,

e. Traditional craftsmanship.

The Austrian intangible cultural heritage is listed in (UNESCOAustria, 2013) and includes 77 entries (as at 2013). The real objects "Boundaries and Boundary Marks" do not fit to this group, certainly not.

\section{THE CRITERIA}

Finally the preconditions for World Heritage shall be summarized shortly, insofar as they relate to this project. They are published in the Operational Guidelines (UNESCO-WHC, 2013) and require for World Heritage properties Outstanding Universal Value (OUV), Authenticity and Integrity, and the existence of a Management Plan for permanent protection and maintenance of the property, especially of the defined OUV. The UNESCO has carefully defined six criteria for the OUV of the cultural World Heritage. At least one of the six must be met. Boundaries and Boundary Marks meet certainly the following three:

Criterion (ii) requires a property to "exhibit an important interchange of human values, over a span of time or cultural area of the world, on developments in architecture or technology, monumental arts, town planning or landscape design". Well-defined and mutually agreed boundaries in a technically as well as legally well-functioning LAS support significantly the exchange of human values in relation to social and economic development as well as on the design of towns and landscapes.

Criterion (iv) requires a property to "be an outstanding example of a type of...technological ensemble which illustrates significant stages in human history". The establishment and permanent maintenance of a nation-wide network of agreed boundaries is a great technical achievement, which is continuously adjusted to reflect the changing needs of human society.

Criterion (vi) requires a property to "be directly or tangibly associated with events or living traditions, with ideas...of outstanding universal significance". Boundaries and boundary marks are living testimonies to social, economic, legal, administrative and technical continuity. In addition, a lot of traditions and rituals are closely linked with boundaries and boundary marks. "And cursed be he who does not respect the boundaries" you wrote already 3000 years ago (Bible, $1500 \mathrm{BC}$ ).

Authenticity and Integrity: Boundaries and boundary marks are protected by constitution and law, practically by the owners, by surveyors and land registry judges. Each alteration is under control and will be documented carefully. The original meaning of a boundary is unchanged, of course developed with time.

Management: Permanent maintenance is in safe hands, organized and observed by Federal Offices according to law. The representative objects of this WH-Project, the boundary stones as well as the others, are listed already as national monuments. It is evident, that the management system already exists.

\section{CONCLUSION}

The proposed Property "Boundary and Boundary Marks" meets all essential requirements of the UNESCO Operational Guidelines for inclusion into the World Heritage List. It supports the UNESCO Global Strategy by a new kind of property, filling a gap on the World Heritage List. It offers the possibility to join the application for countries with minor representation on the List. It considers strongly also the 2014 Florence Declaration of UNESCO regarding the values of Cultural Heritage on building a peaceful and democratic society. This Declaration encourages an in depth reflection on the ethics and processes of heritage management, and a shared concern regarding the challenges that current and future generations will have to deal with. There is no peaceful future of the society without secured Boundaries and Boundary Marks. Therefore all the above can be summarized here in a final statement:

\section{"Boundaries and Boundary Marks" are ideally suited for the UNESCO World Heritage List}

\section{ACKNOWLEDGEMENTS}

The authors thank the other co-members of the Working Group "World Heritage Title for Boundaries and Boundary Marks", Michael Hiermannseder, Gerhard Navratil, Christoph Twaroch (all Vienna); Guenther Abart (Graz); Klaus Hanke, Gerda Schennach (Innsbruck) for their assistance and contributions.

\section{REFERENCES}

Bible, 1500 BC. Deuteronomy 27/17.

Chao Chin-Fang, 2004. Intangible Cultural Heritage in Taiwan: A Comparison with Taketomi Island. Proceedings of the Okinawa International Forum 2004, March 23-28.

ICOMOS-Japan, 2004. Okinawa Declaration. Japan ICOMOS Information 2004/6/2, Tokyo. 
Jokilehto, J.; Cleere, H.; Denyer, S.; Petzet, M., 2005. The World Heritage List: Filling the Gaps - An action plan for the future. ICOMOS Doc. XII, 189 pp.,

http://openarchive.icomos.org/id/eprint/433 (3.June 2014)

Jokilehto, J., 2008. (With contributions by Cameron, C., Peron, M., Petzet, M.). The World Heritage List. What is OUV? Defining the Outstanding Universal Value of Cultural World Heritage Properties. Monuments \& Sites XVI. Baessler, Berlin. ISBN 978-3-930388-51-6.

Krinzinger, F., 2013. Personal communication.

Munjeri, D., 2003. The unknown dimension: An issue of values. ICOMOS $14^{\text {th }}$ General Assembly and Scientific Symposium, Victoria Falls, Zimbabwe.

Paul A., 1988: Steinkreuze und Kreuzsteine in Österreich. (Stone crosses and cross stones in Austria) Regensburg 1988.

Tomaszewski, A., 2003. Tangible and Intangible Values of Cultural Property in Western Tradition and Science. ICOMOS $14^{\text {th }}$ General Assembly and Scientific Symposium, Victoria Falls, Zimbabwe.
UNESCO, 2003. Convention for the Safeguarding of Intangible Cultural Heritage (06.03.2014 :) http://www.unesco.org/culture/ ich/index.php?pg=00006

UNESCO, 2014. The Florence Declaration. $3^{\text {rd }}$ UNESCO World Forum on Culture and Cultural Industries on "Culture, Creativity and Sustaining Development, Research, Innovation and Opportunities". http://en.unesco.org/system/files/Florence Declaration_4 October 2014_en_3.pdf (20.03.2015)

UNESCO-Austria, 2013. List of the intangible cultural heritage in Austria. http://nationalagentur.unesco.at/cgi-bin/unesco.

UNESCO-WHC, 2005. The Struve Geodetic Arc. Nomination file. (6.Aug.2014)

http://whc.unesco.org/uploads/nominations/1187.pdf

UNESCO-WHC, 2013. The operational guidelines for entries in the world heritage list. (07.02.2014)

http://www.unesco.at/kultur/basisdokumente/opguide13-en.pdf

Waldhaeusl, P. et al., 2014. Der Grenzstein als Symbol für das Grundeigentum soll UNESCO Welterbe werden. (The Boundary Stone as a symbol for the Real Property shall become World Heritage) Austrian Journal for Surveying and Geoinformation, 102/1, pp. 11-23. 